\title{
Interprofessional education for first year psychology students: Career plans, perceived relevance and attitudes
}

\begin{abstract}
Undergraduate psychology students have been largely excluded from interprofessional (IP) education initiatives. In contrast to many health professions, undergraduate psychology students do not engage in work placements as part of their degree, and many enter careers outside the health care context. However the collaborative skills gained through an IP education experience may well be beneficial to students who work in this wider context. This research examines whether undergraduate psychology students' views of IP education vary according to their planned career directions, and if so, whether the perceived relevance of IP education mediates the relationships. A sample of 188 Australian university undergraduate psychology students completed an online questionnaire following completion of an IP first year health sciences program. Path analysis indicated that psychology students' attitudes towards IP education are associated with both professional identification and practitioner orientation, fully mediated through the perceived relevance of IP education to future career and study plans. Stronger professional identification and practitioner orientation were associated with greater perceived relevance and more positive and less negative attitudes towards IP education. Placing a stronger emphasis on the generalizability of IP skills taught may increase students' awareness of the relevance outside of the health context, reducing disengagementof students planning alternative careers.
\end{abstract}




\section{IPE FOR FIRST YEAR PSYCHOLOGY STUDENTS}

\section{Introduction}

Interprofessional (IP) education is an essential component in developing a responsive collaborative health workforce (World Health Organization, 2010), international examples of how interprofessional developments have been led including those of Curtin University are now available (Forman, Jones \&Thistlethwaite, 2014) and there is increasing evidence of the effectiveness of IP education interventions (Barr, Helme \& D’Avray, 2014; Reeves, Perrier, Goldman, Freeth \& Zwarenstein, 2013; Reeves, Tassone, Parker, Wagner, Simmons, 2012). Over the last two years, the importance of IP education and collaboration to the future of psychology within the health sector has been highlighted. Psychologists are in danger of being excluded from health care reform initiatives that are emphasising integrated patient care if they continue to work within silos (Cubic, Mance, Turgesen \& Lammana, 2012; Rozensky, 2011). Rozensky (2011) noted that future involvement in IP education and practice may necessitate financial, regulatory and philosophical changes for psychologists, including a reconceptualization of 'clients' (based on Carl Rogers' person-centred therapy conceptualisation of the individual as in control of their own self-improvement) as 'patients' requiring treatment from a health practitioner.

Despite the increased focus on the importance of IP care for the field of psychology, psychology students have been largely absent from the literature on IP education, yet as indicated by the Interprofessional Curriculum Renewal Consortium, Australia (2013) they are the tenth most common group to be included in IP education in Australia. One possible reason for this is the structure of psychology training. In contrast to many other health professions where students graduate from their undergraduate degree equipped to practise, psychology students engage in a broad undergraduate curriculumwith a research rather than practice focus, and require further education and/or supervision before being able to practise 


\section{IPE FOR FIRST YEAR PSYCHOLOGY STUDENTS}

as a psychologist. Only a minority of undergraduate psychology students (38\% in 2012) continue on to further study on completion of their undergraduate degree (Graduate Careeers Australia, 2013) with insufficient places in postgraduate psychology available to meet demand (Voudouris \& Mrowinski, 2010). There are a range of specialist areas within psychology (e.g.health, clinical,counselling, clinical neuropsychology, community, educational and developmental, forensic, organisational and sports psychology)and healthfocused IP education may be of direct relevance to only some of these. Further, many bachelor psychology graduates work outside the field of psychology in legal, social, welfare, business, human resource management, marketing, health and welfare positions. ${ }^{1}$

In summary, the structure of psychology education in Australia does not align with most health professional degrees. In contrast to many other health professions, undergraduate psychology students do not engage in either specific client care skill training or work placements until they commence a Masters level qualification, limiting the opportunity for insitu IP training activities. This creates difficulties for the timing of IP education within the psychology curriculum. If IP education is incorporated in post-graduate training (e.g. clinical psychology masters degrees), postgraduate psychology students may be placed with undergraduate students from other professions (e.g. Priest et al., 2011). If instead, IP education is incorporated within the undergraduate psychology degree, it may not be seen as relevant to students pursuing careers outside of direct client care in health contexts.

To date, no research has examined whether undergraduate psychology students' views of IP education vary according to their planned career directions. Many collaborative skills taught within a health context may be transferrable across occupations (e.g. teamwork; working with 


\section{IPE FOR FIRST YEAR PSYCHOLOGY STUDENTS}

others from different backgrounds).However, if students do not see the relevance of IP education, this may have implications for student satisfaction and course retention.

\section{Background}

The current research examines undergraduate psychology students' perceptions of IP education in relation to intended career directions. The context for this study is a first year health sciences IP curriculum at an Australian university (Brewer, 2011), where students have learnt “with, from and about” (CAIPE 2002) each other's professions. More than 2,300 students from 21 professions complete the one year health sciences IP curriculum ${ }^{2}$ at this university each year. The curriculum provides interprofessional grounding for each student through the completion of five core units (Foundations for Professional Health Practice, Health and Health Behaviour, Human Structure and Function, Evidence Informed Health Practice and Indigenous Culture and Health) completed by all students, two common units completed by smaller groups of professions, and two profession-specific units. Case-based learning encourages a client-centred focus and collaboration between students across the health professions (Jones, Brewer \& Davis, 2011). Surveying students at the beginning of the second year of undergraduate psychology degree provides the opportunity for students to reflect on IP education 'as taught'rather than 'in principle'. This is important as previous research has suggested students' perceptions of IP education may change after exposure (e.g. Pollard, Miers \& Gilchrist, 2005).

\section{Research Questions and Hypotheses}

Two research questions underpinned this research. The first: do psychology students' attitudes towards IP education vary according to their intended career direction? Intended career direction refers to intention to pursue a career in psychology within health settings, and 


\section{IPE FOR FIRST YEAR PSYCHOLOGY STUDENTS}

has been operationalised in terms of professional identification as a psychologist and practitioner orientation. It was hypothesised that professional identification and practitioner orientation would be positively correlated with the perceived relevance of IP education and positive attitudes towards IP education, and negatively correlated with negative attitudes towards IP education.

The second research question: does the perceived relevance of IP education mediate the relationship between intended career direction and attitudes towards IP education? It was hypothesised that the relationship between intended career direction and attitudes towards IP education would be fully mediated by the perceived relevance of IP education to future study and career plans (see Figure 1).

<insert Figure 1 about here>

\section{Method}

\section{Research Design}

This study employed a correlational study utilising an online surveyto measure students' planned careers and attitudes towards IP education.

\section{Participants}

The 188 participants were second year undergraduate psychology students at an Australian University enrolled in a first semester psychological science unit. The majority of students $(161,85.6 \%)$ were enrolled in a Bachelor of Psychology degree ('single degree'), with 27 students (14.4\%) enrolled in a Bachelor of Science (Psychology) and Bachelor of Commerce (Human Research Management and Industrial Relations) ('double degree'). The response 


\section{IPE FOR FIRST YEAR PSYCHOLOGY STUDENTS}

rate was $83 \%$. Reflecting the undergraduate psychology population, most participants were female (73.9\%), Australian (96.3\%), full-time (86.7\%) students. Participants ranged in age between 18 and 61 years $(M=20.97, S D=4.88)$. Two-thirds $(66.5 \%)$ of participantsplanned to work with clients in health care settings in the future, $27.7 \%$ were unsure and $5.9 \%$ did not.

\section{Measures}

Two online questionnaires were created. While the content of the surveys was identical, the ordering of career and IP attitudes measures was counterbalanced in order to detect possible order effects.

Positive IP education attitudes. The nine-item Interprofessional Learning Scale (Pollard, Miers \& Gilchrist, 2004) was used to measure positive attitudes toward IP education. Eight of the items indicate positive attitudes towards IP education (e.g. collaborative learning would be a positive learning experience for all health and social care students.). The Likert-style five-point response scale ranges from (1) strongly agree to (5) strongly disagree. Previous research has demonstrated the scale is internally reliable $(\alpha=.84)$ and has acceptable testretest reliability over a 1-2 week period ( $\mathrm{r}=.86$; Pollard et al., 2004). The concurrent validity has been established through a strong positive correlation $(r=.84)$ with Parsell \& Bligh's (1999) Readiness for Interprofessional Learning Scale (Pollard et al., 2004). In this study the scale had acceptable reliability $(\alpha=.82)$. Possible scale scores range from 9 to 45 , with items recoded so that higher scores reflect higher levels of positive attitudes

Negative IP education attitudes. Existing IP education measures were examined for items that explicitlymeasure negative attitudes towards IP education in early years of the 


\section{IPE FOR FIRST YEAR PSYCHOLOGY STUDENTS}

undergraduate curriculum. Eight items from existing measures were identified and included in the questionnaire (see Table 1). The Likert-style five-point response scale ranges from (1) strongly agree to (5) strongly disagree.Principal axis factoring of the eight items extracted one factor accounting for $42.15 \%$ of variance (see Table 1). The scale has good internal reliability ( $\alpha=.84)$. Possible scale scores range from 8 to 40 , with all items recoded so that higher scores reflect higher levels of negative attitudes.

Practitioner orientation. The Scientist-Practitioner Inventory for Psychology (Leong \& Zachar, 1991) is a 42-item inventory that measures scientist and practitioner interests in psychology. Participants are asked to rate each item in terms of their level of interest in conducting the specified activities in their future careers. Only the 21 item practitioner scale is of interest in this research. An example item on the practitioner scale is "conducting group psychotherapy sessions". The Likert-style five-point response scale ranges from (1) very low interest to (5) very high interest. Possible scale scores range from 21 to 105, with higher scores representing higher interest in practitioner activities. Previous research indicates the scale has good internal reliability ( $\alpha=.88$ to .94; Holmes \& Beins, 2009; Leong \& Zachar, 1991), with comparable findings found in this study $(\alpha=.90)$.

Professional identification as a psychologist. The Professional Identity Scale (Adams, Hean, Sturgis \& Clark, 2006) is a 9-item measure of the strength of professional identity. The measure comprises 6positively (e.g. I feel like I am a member of this profession) and 3negatively (e.g. I try to hide that I am studying to be part of this profession) worded items. Participants respond to each item on a 5 point Likert-style scale ranging from (1) never to (5) very often. Possible scores range from 9 to 45 , with higher scores representing a more positive professional identity. Previous research indicates the scale is unidimensional and internally 


\section{IPE FOR FIRST YEAR PSYCHOLOGY STUDENTS}

reliable ( $\alpha=.79$, Adams et al., 2006).In this study the measure had acceptable internal reliability $(\alpha=.79)$.

Perceived IP education relevance. No measure of the perceived relevance of IP education to future careers could be located in a search of the published academic literature. Four items were developed by the researchers. The Likert-style five-point response scale ranges from (1) strongly agree to (5) strongly disagree. Principal axis factoring of the four items extracted one factor accounting for $63.82 \%$ of variance (see Table 2 ). The first three items were recoded so that higher scores reflect higher levels of perceived relevance. The scale has good internal reliability $(\alpha=.78)$. Possible scale scores range from 4 to 20 .

Demographic variables. Single item measures of age, gender, degree, year of study, parttime/full-time status, international/domestic student and intention to work within health care settings in direct client care roleswere included in the questionnaire.

IP education Comments. One open-ended question was placed at the end of the questionnaire: do you have any comments you would like to make about IP education in relation to your planned career?

\section{Procedure}

Students were recruited through a second year psychology participant pool. Upon consenting to participate, students were randomly assigned to one of the two versions of the questionnaire. Students opting not to participate in this or other research were offered an alternative written activity.The questionnaires were available between March and June 2013. 


\section{IPE FOR FIRST YEAR PSYCHOLOGY STUDENTS}

At the end of the survey period questionnaire data for 201 participants was downloaded into SPSS (v. 20) for preliminary analysis. Ten cases were deleted as the survey was not completed and a further three cases deleted where the student was enrolled in a degree other than psychology, leaving 188 cases for analysis. Missing data was replaced using mean scores.

\section{Analysis}

Quantitative data was analysed using SPSS and LISREL. To address the first research question, a correlation matrix was produced. To address the second research question, the hypothesised full mediation model was tested against a partial mediation model. This analysis was conducted using path analysis in LISREL to enable measurement error to be taken into account.

Comments by single and double degree psychology students in response to the open ended question were analysed using content analysis. Minor typographical errors were corrected to increase the readability of quotes.

\section{Ethical considerations}

The study received approval from Curtin University Human Research Ethics Committee before it commenced.

\section{Results}

Descriptive statistics for each of the scale measures are presented in Table 3 and a correlation matrix of scale in Table 4. As hypothesised, professional identity and practitioner orientation were significantly positively correlated with perceived relevance and positive attitudes 


\section{IPE FOR FIRST YEAR PSYCHOLOGY STUDENTS}

toward IP education (all medium effect sizes). Professional identity was significantly negatively correlated with negative attitudes (small effect size), but practitioner orientation was not.

<Insert Tables $3 \& 4$ about here>

Path analysis models testing full and partial mediation are presented in Figures 2 and 3, with fit indices for each model presented in Table 5.

<Insert Table 5 and Figures 2-5 about here>

The two models account for similar percentages of variance in attitudes towards IP education (62\% positive attitudes; $48 \%$ partial mediation/44\% full mediation model negative attitudes). Using Cohen's conventions, these are large effect sizes. Professional identification and practitioner orientation combined account for $21 \%$ of variance in the perceived relevance of IP education in the partial mediation model and $20 \%$ in the mediated model (medium effect sizes). An examination of the fit indices indicates that the full mediation model provides a better fit to the data than the saturated partial mediation model, and as the more parsimonious model should be preferred.

\section{Open ended comments}

Twenty nine students enrolled in a Bachelor of Psychology single degree and 10 students enrolled in a 'double degree' provided comments about IP education. The large majority of comments were positive, focusing on IP care as optimal client care: "a united, 


\section{IPE FOR FIRST YEAR PSYCHOLOGY STUDENTS}

interprofessional plan of health presents the best opportunity to deliver the best client care"; and an improvement over current practices:

"IP education is important in this day and age as it allows different faculties of health science personnel to work together which will hopefully allow to create a better health care system for the public."

Students highlighted the need for health professionals to communicate and work together:

"OT's, psychologists, psychiatrists may all be working with the same patient at the same time, meaning they need to know how to effectively communicate with each other, in order to manage and give their patient the best care possible."

The relevance of IP education to students planning to be psychologists was highlighted; "as a psychologist it is very important to have an interpersonal relationship with other professions. That will help you having information about your clients"; along with the relevance of the material covered, "it would be helpful as a psychologist to have basic knowledge of all health science information.” IP education exposed students to differing professions, broadening their understanding of different paradigms, "it made me think about things that I don't think I would have, in particular: everyone having a 'world view', I believe this open mindedness helps people become better professionals." Some students saw value in IP education regardless of their planned future careers, "I think it's important to have a wide knowledge regarding other health professions regardless of your chosen profession."

However, some students queried the relevance of IP education to future careers, "whether it is relevant or not is highly influenced by what branch of psychology I choose to go into"; with concern raised over the singular focus on clinical psychology within health settings. Double degree students raised particular concerns about the applicability of IPE to intended careers, “As I plan on doing HR I don't think IP education is relevant to my career unless I become a psychologist." The competing paradigms of commerce and psychology were noted: 


\section{IPE FOR FIRST YEAR PSYCHOLOGY STUDENTS}

"Business School and Health Sciences do not mix effectively. Very different approaches and I feel lost sometimes in the middle."

The timing of IP education was questioned by some students, who felt that first year students had insufficient profession specific knowledge to fully engage in IP education, "I felt in first year people did not know much about their degree. Or at least not enough that it really felt like working on an IP team" and "we end up relying on our pre-conceived ideas/stereotypes of what other profession do (including own own)".Some students recommend IP education be moved to later years "when students actually have some sort of knowledge about their own field to bring to the table", as "true IP relationship education I imagine happens as I progress closer towards having a career." In direct contrast, one student commented on the appropriateness of IP education in first year, questioning the practicality in later years:

"IP education was useful during 1st year as there were a number of core subjects common to several streams. I do not know how effective it can be in later years due to the specialised nature of the studies."

Some students expressed general dissatisfaction with IP education; "I feel there are better uses of my educational timethat could make me more prepared for my career than IP education"; the relevance of what was taught within the IP education units; "the information covered in the units should be more relevant and interesting which would encourage better relationships in future careers", or the way it was taught: "I think the IP classes were pointless. I didn't learn anything useful about the other professions or how they work." 


\section{IPE FOR FIRST YEAR PSYCHOLOGY STUDENTS}

\section{Discussion}

The aim of this research was to examine psychology students' attitudes towards IP education in relation to their intended career directions. The results indicate that psychology students' attitudes towards IP education are associated with both professional identification and practitioner orientation, mediated through the perceived relevance of IP education to their future career and study plans. Stronger professional identification and practitioner orientation were associated with greater perceived relevance and more positive and less negative attitudes towards IP education. This finding is in accord with what Kitto, Nordquist, Peller, Grant and Reeves (2013) describe as "place" and the individual's preference to invest in what they regard as their preference for future employment when studying on interprofessional programmes.

Scores on the two measures of career direction; professional identity and practitioner orientation; were both above the midpoint of the scales, indicating positive professional identification and a practitioner orientation. This is consistent with previous research reporting strong professional indication in first year students across occupational groupings (Adams et al., 2006). The two measures were moderately correlated ( $r=.45$ ) suggesting that a practitioner orientation is a central component of professional psychology identification.

Scores on the perceived relevance measure were also above the mid-point indicating that on average students agreed that IP education was relevant to them. Both measures of intended career direction were positively associated with perceived relevance of IP education, indicating that practitioner orientation and professional identification are key predictors of the perceived relevance of IP education to future studies and careers. However, combined they explain only $20 \%$ of the variance in perceived relevance of IP education, suggesting other 


\section{IPE FOR FIRST YEAR PSYCHOLOGY STUDENTS}

factors are also important in determining relevance. Comments provided in response to the open-ended question suggest that these factors might include the professions involved, the content of the material taught, and not knowing enough psychology to be able to meaningfully contribute.

Students enter health courses in universities with stereotyped views of different health professionals (Tunstall-Pedoe, Rink \& Hilton, 2013). In the absence of specific knowledge about the role of psychologists and how this is differentiated from other professions, students may resort to applying and perpetuating stereotypes. This provides a strong argument for delaying IP education until after the first year of study, or providing vertical integration of IP education across years.

Perceived relevance was strongly associated with both positive attitudes and negative attitudes. Scores were above the mid-point of the positive attitudes scale and below the midpoint on the negative attitudes scale, indicating than on average students held positive attitudes towards IP education. This was also reflected in the qualitative comments, with the majority of comments from single degree psychology students supporting IP education. Students recognised the need for health professionals to communicate and work together. IP education was perceived as relevant to working as a psychologist, providing exposure to different professions, contributing to an understanding of the workplace and developing the interpersonal skills necessary for IP care. As such, IP education is serving the purpose of orienting students towards working with other health care professionals to provide integrated care, consistent with current health care initiatives (Cubic, Mance, Turgesen \& Lammana, 2012; Rozensky, 2011) 


\section{IPE FOR FIRST YEAR PSYCHOLOGY STUDENTS}

The mediation model tested has strong explanatory power and increases our understanding of why some psychology students do not embrace IP education. Students with lower professional identification and less interest in practitioner activities perceive less relevance for IP education and hold stronger negative attitudes and weaker positive attitudes towards IP education. Comments from 'double degree' students referred to the tension between health sciences and commerce, the preference for IP activities with students beyond health science and the perceived limited relevance of health-focused IP education for careers in human resource management.

If attitudes toward IP education are largely driven by the perceived relevance of IP education, what can be done to change the attitudes of those students who do not see the relevance of IP education to their future study or career aspirations? In a large IP education program catering for multiple professions it is not logistically feasible to specifically cater for individual subprofessions through, for example, providing relevant scenarios and examples for each. However, IP collaboration, including the ability to effectively work with and learn from professionals in other professions, is highly valued in all work places, not just within health settings. We recommend teaching staff focus on the relevance of IP collaboration in all workplaces, emphasising the generalizability of the skills learned in the IP first year to other contexts. This may act to increase the perceived relevance of IP education and further engage students across professions who do not currently envisage a career as a psychologist or within health settings.

Alternatively, it could be argued that IP education taught within a health context is relevant only to those students planning a career within health settings, and students planning alternative careers may be better served by an alternative. This may be particularly the case 


\section{IPE FOR FIRST YEAR PSYCHOLOGY STUDENTS}

for students completing 'double degrees', who we risk disenfranchising if we cannot actively engage them in their first year of study. The recommended change in emphasis to the generalizability of IP collaboration to all employment settings may increase the perceived relevance of IP education for these students.

The findings from this research provide clear evidence of the mediating role of perceived relevance in the relationship between intended career direction and attitudes toward IP education. Strengths of the study include the high response rate and statistical analysis that accounts for measurement error. However, the research is limited by the use of one-point-intime data to examine causal pathways. Future longitudinal research is required to track changes in the key variables over time. A further limitation is the focus on only one discipline within the 23 disciplines included in the IP first year. While this model may be of use in other disciplines that offer a range of possible career paths outside of direct health care settings (e.g., molecular genetics and biotechnology, social work), it is possible that in disciplines where completion of an undergraduate degree leads directly to professional positions within the health care sector (e.g., nursing, physiotherapy) the model depicted here is not useful as there is likely to be little variance in perceived relevance of IP education. Results may also vary according to the 'mix' of disciplines included within an IP program and students' perceptions of the likelihood of future professional engagement with the professions included. In order to determine the generalizability of the findings beyond psychology students, future research is required that applies the model to students from a range of professions.

\section{Concluding comments}




\section{IPE FOR FIRST YEAR PSYCHOLOGY STUDENTS}

In this paper we presented a model of the relationship between intended career direction and attitudes towards IP education, proposing the perceived relevance of IP education to future study and career plans as a mediator. The model was supported in a sample of undergraduate students, and was able to successfully predict both positive and negative attitudes. It is recommended that teaching staff place a stronger emphasis on the generalizability of the IP skills taught, to increase students' awareness of the relevance to workplaces outside of the health context.

\section{Notes \\ ${ }^{1}$ See: http://www.graduatecareers.com.au/Research/GradJobsDollars/BachelorAll/Psychology/index.htm \\ ${ }^{2}$ Students from the following groups participated in the curriculum: "exercise, sports and rehabilitation science; food science and technology; health information management; health promotion; health, safety and environment; health sciences; human biology preclinical; laboratory medicine; medical imaging science; midwifery; molecular genetics and biotechnology; nursing; nutrition; occupational therapy; oral health therapy; paramedicine; pharmacy; physiotherapy; psychology; social work and speech pathology" (http://healthsciences.curtin.edu.au/faculty/ipe faqs students.cfm )}

\section{Declaration of Interest}

The authors report no declarations of interest.

\section{References}

Adams, K., Hean, S., Sturgis, P. \& Clark, J.M. (2006). Investigating the factors influencing professional identity of first-year health and social care students. Learning in Health \& Social Care, 5(2), 55-68.

Barr, H., Helme, M. \& D'Avray, L. (2014). Review of interprofessional education in the United Kingdom, 1997- 2013. London: CAIPE

Brewer, M. (2011). Curtin University's Faculty of Health Sciences Interprofessional Capability Framework. Perth: Curtin University. Retrieved from http://healthsciences.curtin.edu.au/local/docs/IP Capability Framework booklet.pdf

CAIPE (2002) Centre for the Advancement of Interprofessional Education. Retrieved from: http://www.caipe.org.uk/about-us/defining-ipe/

Cubic, B., Mance, J., Turgesen, J.N., \& Lamanna, J. D. (2012). Interprofessional education: Preparing psychologists for success in integrated primary care. Journal of Clinical Psychology in Medical Settings, 19, 84-92. doi: 10.1007/s10880-011-9291-y 
Forman, D., Jones, M. \& Thistlethwaite, J. (Eds).(2014).Leadership development for interprofessional education and collaborative practice.New York, NY: Palgrave MacMillan

Graduate Careers Australia (2013). Graduate destinations 2012: A report on the work and study outcomes of recent higher education graduates. Melbourne, Australia: Graduate Careers Australia.

Holmes, J.D. \& Beins, B.C. (2009). Psychology is a science: At least some students think so. Teaching of Psychology, 36, 5-11. doi: 10.1080/00986280802529350.

Interprofessional Curriculum Renewal Consortium, Australia. (2013). Interprofessional education: a national audit report to health workforce Australia. Centre for Research in Learning and Change: University of Technology Sydney: Sydney.

Jones, S., Brewer, M. \& Davis, M. (2011). Transforming the FYE in Health Sciences: development and evaluation of an interprofessional first year curriculum. Paper presented at the $14^{\text {th }}$ pacific Rim FYHE Conference, Fremantle, Western Australia,

Kitto, S. Nordquist, J. Peller, J. Grant, R and Reeves, S. (2013). The disconnections between space, place and learning in interprofessional education: An overview of key issues. Journal of Interprofessional Care, 27(52), 5-8.

Kline, R.B. (2005). Principles and practice of structural equation modelling ( $2^{\text {nd }}$ ed.). New York: Guildford Press

Leong, F.T. \&Zachar, P. (1991). Development and validation of the Scientist-Practitioner Inventory. Journal of Counselling Psychology, 38, 331-341.

Morison, S. \& Jenkins,J. (2007). Sustained effects of Interprofessional shared learningon student attitudes to communication and team working depend on shared learning opportunities on clinical placement as well as in the classroom. Medical Teacher, 29, 450456. doi:10.1080/01421590701477381

Parsell, G. \& Bligh, J. (1999). The development of a questionnaire to assess the readiness of health care students for interprofessional learning (RIPLS). Medical Education, 33, 95-100.

Pollard, K., Miers, M.E. \& Gilchrist, M. (2004). Collaborative learning for collaborative working? Initial findings from a longitudinal study of health and social care students. Health and Social Care in the Community, 12, 346-358.

Pollard, K., Miers, M.E. \& Gilchrist, M. (2005). Second year scepticism: Pre-qualifying health and social care students' midpoint self-assessment, attitudes and perceptions concerning interprofessional learning and working. Journal of Interprofessional Care, 19(3), 251-268.

Priest, H.M., Roberts, P., Dent, H., Hunt, T., Weston, D., Chell, A., Blincoe, C \& Armstrong, C. (2011). Preparing for collaborative working in mental health: An interprofessional education project with clinical psychology trainees and nursing students. The Journal of Mental Health Training, Education and Practice, 6, 47-57. doi:10.1108/17556221111136161 


\section{IPE FOR FIRST YEAR PSYCHOLOGY STUDENTS}

Reeves, S., Perrier, L., Freeth, D. \& Zwarenstein, M. (2013). Interprofessional education: Effects on professional practice and healthcare outcomes (update). Cochrane Database of Systematic Reviews 2013, Issue 3. Art. No.: CD002213. doi:10.1002/14651858.CD002213.pub3.

Reeves, S. Tassone, M. Parker, K Wagner, S.J., \& Simmons, B. (2012) Interprofessional education: An overview of key developments in the past 3 decades. Work, 41, 233-245.

Rozensky, R.H. (2011). The institution of the institutional practice of psychology: Health care reform and psychology's future workforce. American Psychologist, 66, 797-808. doi:10.1037/a0024621

Tunstall-Pedoe, S., Rink, E. \& Hilton, S. (2003). Student attitudes to undergraduate interprofessional education. Journal of Interprofessional Care, 17, 161-172. doi:10.1080/1356182031000081768

Voudouris, N. \& Mrowinski, V. (2010). Alarming drop in availability of postgraduate psychology training. InPsych: The Bulletin of the Australian Psychological Society, 32(2), 20-23.

World Health Organization. (2010) Framework for action on interprofessional education and collaborative practice. Retrieved from

http://who.int/hrh/resources/framework_action/en/index.html 